found only in Lake Tahoe, California, spends all its life underwater at depths of more than 60 metres.

An innovation in this volume of the continuing Red Data Book series is a section on Threatened Communities. Eleven examples are given of tropical forests, caves, wetlands, dry biomes, marine environments, and areas with unusual diversity of species. They illustrate situations in which human activities may endanger large but unique invertebrate populations.

The listings - of use to environmental planners, scientific research workers, teachers, and reference librariesconstitute a kind of 'Guinness Book of Records' for invertebrates, and make fascinating reading. Thus the book identifies the world's largest earwig (nearly $8 \mathrm{~cm}$ long, found on St Helena Island), largest butterfly (up to $25 \mathrm{~cm}$ across, found in Papua New Guinea), largest bee (39 $\mathrm{mm}$ long, found in Indonesia), largest land invertebrate (a species of crab which weighs up to five $\mathrm{kg}$ ), and the largest clam (the giant clam of southern waters, with a diameter up to 1.4 metre, a weight over $200 \mathrm{~kg}$, and a life-span of more than a century).

Many invertebrates which may be declining are important in medical research. Of the 5,000 different kinds of sponges, some have anti-inflammatory and anti-viral properties, amongst 'an amazing diversity' of important possibilities, according to the Authors. The medicinal leech is the source of a compound that may be of value in treating heart-disease. The American Cancer Society sponsors research on a microscopic protozoan animal to study what causes cancerous cells to divide, whilst the blood of horseshoe crabs is used extensively in biomedical research. Similar examples abound in the book.

Every creature has its place in the grand scheme of things, whether or not this has yet been revealed to Man, the IUCN Invertebrate Red Data Book suggests. Man's invasion into marine and forest habitats and wholesale chemical assault on the invertebrate world is decimating the ranks of these neglected and intriguing creatures, with potentially adverse effects on the balance of Nature on which Man hismself depends.

The book, compiled jointly by Susan Wells, Robert Pyle, \& Mark Collins, with drawings by Sarah Anne Hughes, is available at about US $\$ 20.00$ plus postage from the Conservation Monitoring Centre, 219 (c) Huntingdon Road, Cambridge, England, UK; from IUCN, Avenue du Mont-Blanc, 1196 Gland, Switzerland, and from Unipub, Box 433 Morray Hill Station, New York, NY 10016, USA. The book was prepared with financial assistance from the World Wildlife Fund and the United Nations Environment Programme.

DONALD AllaN
IUCN
Avenue du Mont-Blanc
I196 Gland
Switzerland.

\title{
Production of Rubber by Desert Plant Nearly Doubled in Greenhouse Experiments
}

Scientists have practically doubled the production of rubber from Guayule (Parthenium argentatum, Compositae) by chemically treating that desert plant ${ }^{*}$ in greenhouse experiments - an accomplishment that could be a big step towards providing a domestic source of rubber and freeing the United States from dependence on Southeast Asian sources. The compound which the scientists used increases rubber production by regulating the metabolic reactions which lead to the formation of rubber in the plant. They believe that the same technique might be applicable in other cases, including some foodcrops.

This important advance in plant biochemistry was made by a team headed by Dr Chauncey $R$. Benedict, of Texas A\&M University, and Dr Henry Yokoyama, of the US Department of Agriculture in Pasadena, California. They reported their findings to the National Science Foundation's Division of Physiology, Cellular and Molecular Biology, which had funded the research.

Several years ago, Dr Yokoyama discovered compounds that induced pertinent biological activity in plants. Doubling the synthesis of rubber in Guayule was accomplished by applying a bioregulator, dichlorophenoxy-triethylamine (DCPTA), to the plant.

Guayule is a hardy desert shrub that grows naturally in the harsh climate of northern Mexico and southwestern Texas. The extremely drought-resistant plant has an extensive root system which gathers what little moisture

\footnotetext{
* See, for example, the chapters on 'Botany of Parthenium' and 'Production of Rubber from Guayule (Parthenium)' in the late LoRen G. Polhamus's Rubber: Botany, Production, and Utilization. (World Crops Books series, Gen. Ed. Nicholas Polunin.) Leonard Hill, London, \& Interscience Publishers, New York: xvii +448 pp., 64 plates, 7 figs in text, and XX Tables, 1962.-Ed.
}

there is in the soil. The plant is usually between two and three feet high $(61-91 \mathrm{~cm})$, its silvery leaves giving it an ornamental appearance.

'The chemical stimulation of rubber synthesis in Guayule was apparent at 60 days following application of the bioregulator,' Dr Benedict reported to the National Science Foundation. 'Throughout the growth-period of 60 to 120 days after the application of DCPTA, the treated plants contained a higher total rubber content and a higher percentage of rubber than the control plants. After 120 days of growth, the control plants contained $2.83 \%$ rubber and the DCPTA-treated plants contained $5.23 \%$ rubber. There was about a twofold chemical stimulation of rubber synthesis in the treated versus the control plants throughout the 60 to 120 -days' period.'

Spraying the DCPTA on the foliage of Guayule plants increases rubber synthesis over a longer growth-period than normally, Dr Benedict reported, adding that, in natural stands, rubber is synthesized only during the autumn and winter months, when the plants experience the low night temperatures that are necessary to stimulate rubber formation.

'A chemical treatment of Guayule with a bioregulator [such as] DCPTA,' Dr Benedict said, 'may make possible the production of rubber in Guayule plants commercially grown in regions where conditions are optimal for good vegetative growth, but the night temperatures are not low enough to induce rubber production. Such regions include [parts of] California, Arizona, New Mexico, and Texas.' Details of this work are being published in the journal Plant Physiology.

RALPH KAZARIAN
National Science Foundation
$1800 \mathrm{G}$ Street
Washington
DC 20550, USA.

